\title{
Application of Price Discrimination in the Network Team Purchase
}

\author{
Yanqin Zhu ${ }^{1, \text { a }}$,Jun Zhang ${ }^{2, \text { b }}$,Jiajia Wang ${ }^{3, c}$ \\ Wuhan University of Technology,430070,Wuhan China \\ Wuhan University of Technology,430070,Wuhan China \\ Wuhan University of Technology,430070,Wuhan China \\ a email:1324117519@qq.com, ${ }^{b}$ email: zhangjun@whut. edu.cn, ${ }^{c}$ email:875432945@qq.com
}

Keywords: network team purchase(NTP), price discrimination,NTP models

\begin{abstract}
With the development of the network team purchase(NTP), the analysis on the theory of NTP will be more and more important. Since NTP is a new consume model, there are few researches on it up to now. Network team purchase in the development process from scratch, there have been a variety of modes, which have their own characteristics, to promote the development of network buy plays a big role. But these will not necessarily develop in parallel mode and go on to analyze the characteristics and influence these patterns, recognize the development direction of network buy, for better and faster to buy influence to improve network has very important significance. All kinds of NTP models are studied comprehensive respectively and then the characters of these NTP models are compared in this paper. In the same time, by means of intensive observation and comprehension, better model improving the development of NTP is found out.
\end{abstract}

\section{Introduction}

Why study the influence of Network team purchase? Because this is a correct understanding of the market value of Network team purchase, effectively construct the premise and basis of competitiveness. It is often said, to solve strategic problems than tactical issues important decision angle, which is a problem because of the strategic objectives and determine the direction of tactical operations, lost the tactical objectives and direction anyway delicate operation is also blind, and the lack of reliable significance.

Customers buy network behavior is occurring on the Internet as a link to the information collectively. With the Network team purchase consumption patterns Appears, this theory also done some preliminary research and discussion, and the connotation buy mode network made different definitions[1].

Some scholars believe that the Internet is an extension of the traditional buy, thus starting the formation of the following understanding: that organizations buy Procurement, also known as collective procurement (referred to as the Central Purchasing). Usually refers to a single buyer (including individual consumers and consumer units) by media organizations together to form shopping groups, and effectively ordering large quantities from suppliers at below market price to get the product or service purchase behavior. Network team purchase is the way to buy a new form, but with the traditional buy and not essentially different. Network team purchase through the Internet channel, will have the same intention to buy consumer organizations together. .

The above analysis are about to buy individual researchers from the network point of view and for-profit sponsors of describing the purpose of the network to buy the perspective of Network team purchase organizers made phenomenon. Based on the above study, this paper argues, can be defined 
as follows Network team purchase: Network team purchase is about the organization or individual to meet the specific needs of consumers, the convenience of using the Internet platform features through Over voluntary groups, information sharing, joint purchasing, in order to reduce transaction costs and risks, access to consumer surplus maximizing a kind of rational behavior. . Due to the current logistics and integrity, etc. , currently mainly in the city buy network-based, that is merely providing convene negotiations on services and products for the same in a city where consumers buy the initiator[5].

\section{Network team purchase model market existing mechanism}

Market Demand for Traditional Products Is Not Fully Satisfied. Assuming the traditional market is monopolistic competitive market, then in the market, companies have to produce a product of the existence of different demand curves, assuming A corporate demand curve $p=a-b q$ (Fig. 1), when there the market equilibrium point $\mathrm{E}$, the market price for a corporate PA, the market can only meet $q_{A}=\frac{a}{b}-\frac{p_{A}}{b}$ a demand for consumer products, but there $\frac{p_{A}}{b} \mathrm{a}$ consumer has not been met. Similarly, the B, C, D, . , and other enterprises, when the price is PB, PC, PD, . when there $\frac{P_{B}}{b_{B}} 、 \frac{P_{C}}{b_{C}}$ 、 $\frac{P_{D}}{b_{D}}, \ldots$ not satisfy consumers. Therefore, assuming that there are $\mathrm{n}$ the production of the product on the market, then for each company in the market equilibrium price $\{\mathrm{PA}, \mathrm{PB}, \mathrm{PC}, \ldots\}$, there are at leasta $_{H}=\min \left\{\frac{\mathrm{P}_{\mathrm{A}}}{\mathrm{b}_{\mathrm{A}}}, \frac{\mathrm{P}_{\mathrm{B}}}{\mathrm{b}_{\mathrm{B}}}, \frac{\mathrm{P}_{\mathrm{C}}}{\mathrm{b}_{\mathrm{C}}}, \ldots\right\}$, such that there is on the market for at least $\mathrm{q}=\mathrm{nqH}$ a consumer is not satisfied.

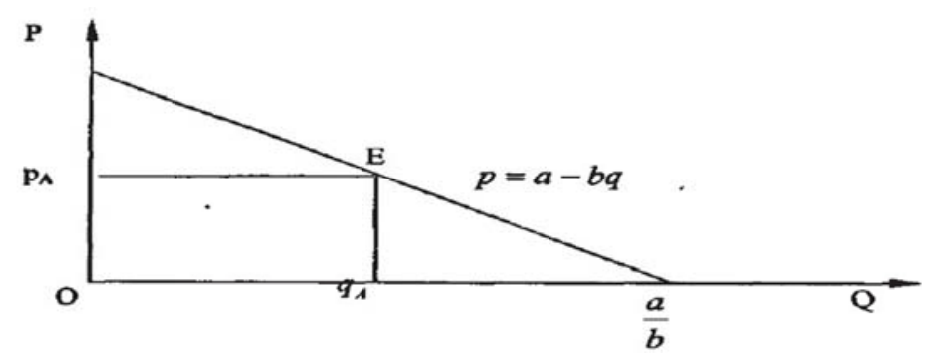

Fig. 1 company A's market demand curve

the Reason that Some Consumers Could Not Be Satisfied. We know that the goal is to maximize corporate profits, profit maximization condition enterprises are operating guidelines to follow. This criterion is to combine the analysis of benefits and costs derived, specifically: the marginal revenue equals marginal cost. Namely: $\mathrm{MR}=\mathrm{MC}$, the largest corporate profits.

This is because, if MR> MC, it means a higher cost of sales per unit of product revenue increased more than the increase, therefore, in order to increase profits, companies will increase production until $\mathrm{MR}=\mathrm{MC}$ so far. If $\mathrm{MR}<\mathrm{MC}$, it shows an increase in sales per unit of product revenue increased less than the increase in costs, in other words, a decrease in the sales per unit of product revenue decreased less than the reduction in costs, and therefore, in order to increase profits, companies will reduce production and sales until $\mathrm{MR}=\mathrm{MC}$ so far. (Fig. 2) 


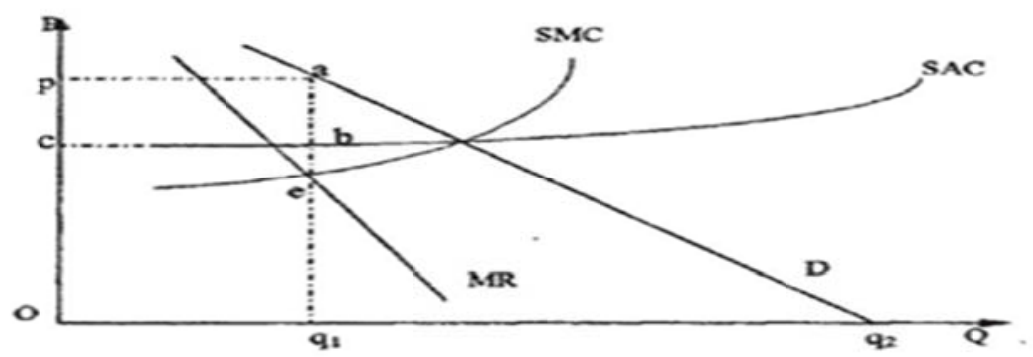

Fig. 2 Monopolistically competitive firm's short-run equilibrium

From the above analysis shows that in the event of profit under marginal revenue equals marginal cost conditions, can get the maximum profit. In this case, neither increase in production enterprises not reduce production yield, production is relatively stable, it is also known as $\mathrm{MR}=$ MC producer equilibrium conditions[9].

In Fig. 2, assume that a company known their demand curve D, the marginal revenue curve and the short-run marginal cost curve SMC, in order to achieve the maximum or minimum loss of profits, business in accordance with the principle of marginal cost equals marginal revenue, $\mathrm{MR}=$ SMC to determine their own production, which is then used to identify the demand curve is consistent with this production price, set at the end of the output Q, P Price is fixed, the firm realized the short-term equilibrium. At this point, monopolistic competition, companies may obtain maximum profits, profits may be zero, or it may suffer minimal losses. In general, the monopolistic competitive market, the products, there are some differences exist between the short-term economic profit enterprise.

Vendors to Join the Network Needs to Meet the Conditions of the Buy Mode. We can see from Fig. 2, when companies in traditional markets in the short term to achieve a balanced, the number of consumer organizations meet for $\mathrm{q} 1$, the number of enterprises have yet to meet the consumer is (q2-q1). In the case of corporate demand curve does not change, the enterprise marginal product curve does not change. If companies want to achieve equilibrium point $e$ of the changes, the short-run marginal cost and average cost of short-term business needs change. As can be seen from Fig. 2, only the SMC and SAC curve down, companies will increase the product launch to the market, the company's market equilibrium point will appear in e1 place, the number of companies that meet consumers realize increased[3].

From the above it can be seen that if companies want to get new revenue in new consumers without compromising the original consumer q1 from the acquired interests, consumers need to ensure that new additions to the original consumer can distinguish, which can be divided into two different markets, two markets in theory, there is no overlap with each other, and the two markets have different short-run marginal cost curve and average cost curve, ie SMC, SMC1 and SAC1, SAC. (Fig. 3) from the foregoing analysis may know, the network has to buy a certain extent, the above conditions, it can achieve profitable growth through the network to buy the way.

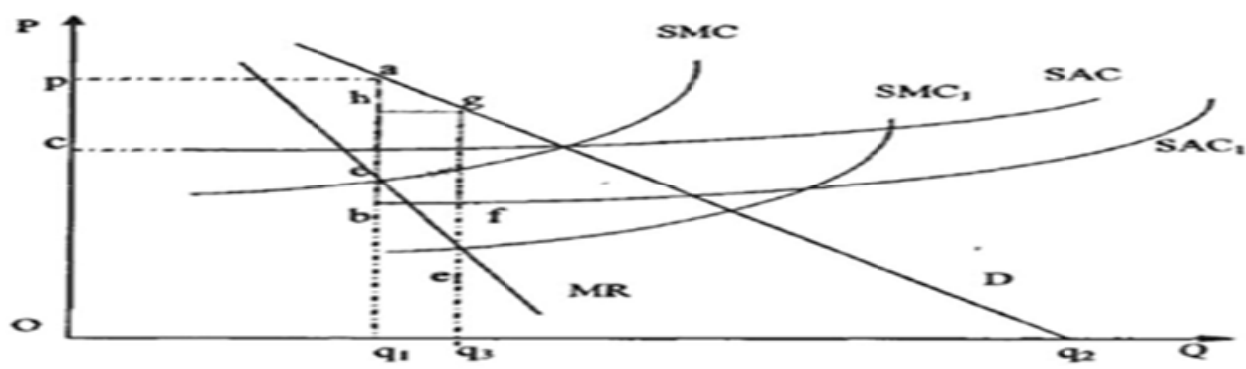

Fig. 3Network team purchase short-term business model of monopolistic competition equilibrium

\section{Network team purchase improving product yield principle analysis}

Network Model Can Buy Products to Expand Market Share and Increase Overall Profits. Network team purchase market offers manufacturers can't obtain in the traditional markets of consumer 
groups. Buying Online is convened by consumers on the Internet and realized, due to the presence buy, consumers can get low-priced products, so consumers buy participating in the network are usually price sensitive populations, and the network cut to buy from the group to the consumer. Buying online companies can provide a suitable mechanism for the operation of the market price discrimination Environment.

In the traditional market, companies often use price discrimination strategy to achieve the different target group marketing. Third-degree price discrimination which can be separated from each other in different markets to achieve.

Buy online is the realization of consumer cooperation achieved through the Internet. Internet as the new battleground market impact has been more and more manufacturers are concerned, but in the Internet product marketing is often blind, because the manufacturers are often not able to determine consumer preferences of the target group. But the emergence of network buy, basically an important feature to determine consumer price sensitivity. The best evidence that the consumer price sensitive in that it can in order to get the network to buy cheap and bear the cost of waiting time, therefore, the implementation of the network buy mode low-cost strategy for manufacturers to be able to successfully run a profitable price discrimination strategy.

The purpose of the network enables manufacturers cheap buy mode while profit growth. When a vendor to join the network buy mode, buy the market if the network has only this one vendor, the vendor is a network buy monopoly in this market, manufacturers need to consider how the network buy product pricing.

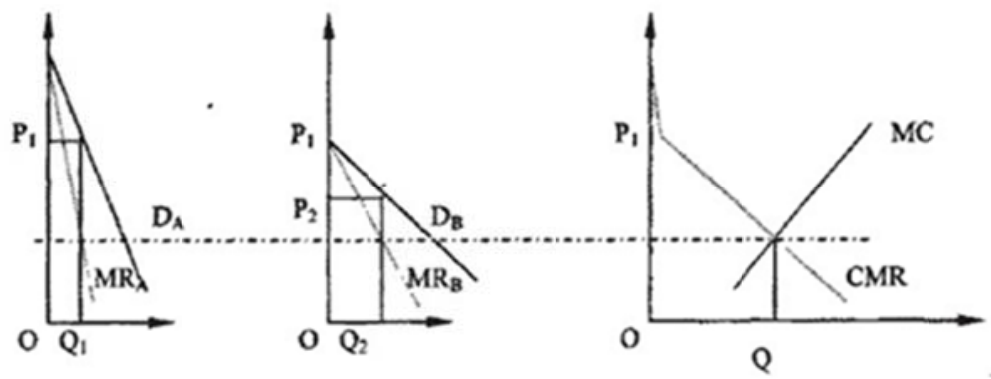

Fig. 4 Demand curves in different markets

From the above analysis shows that, due to the network buy mode there are price sensitive consumer, so the consumer network buy high price elasticity of demand curve in the traditional market makers demand curve and buy mode network is different (Fig. 4).

Determine the Manufacturers in the Production. Fig. 4, we assume that the two markets the product is homogeneous. The vendor must consider the marginal cost of his entire output, regardless of the market in which to sell. To maximize profits, he needs to make his production and sales is equal to the marginal cost of production in the two markets together combined marginal income CMR, CMR is yield curve and MC curve intersects the point. [10] Combined income of the two markets (CMR) by the two curves are two marginal revenue curve obtained by adding the market : the marginal revenue can be drawn separately for each of the market demand curve MRA and according to traditional markets and market network buy MRB. MRA take a little curve in the office, you can come to the market with the A marginal revenue equal to marginal revenue yields in the B market. Marginal revenue corresponding to either yield two markets together, you can draw the entire production corresponding to the marginal revenue monopolist. CMR in MC intersects with the point of the corresponding output in Fig. 4, that is, manufacturers can achieve maximum yield profits. $0 \mathrm{Q}=0 \mathrm{Q} 1+0 \mathrm{Q} 2$. In this production, the production of the final cost of an additional unit of product (MC) is exactly equal to the market in any product revenue of the unit can get additional (MRA or MRB) to sell.

\section{Conclusion}

The above reasoning, the assumption that the market can buy for network vendors need sufficient 
number of consumers, and thus manufacturers can make decisions based on their own to maximize profits, but sometimes because the network can't buy so much in a short time the price sensitive called up, so the slope of the demand curve may buy a smaller network, then manufacturers will not be able to achieve the intended purpose whole constitution. Therefore, great efforts to cultivate a network buy the market is critical.

From this example also shows that selecting the right product to buy network buy appropriate sized enterprises is also critical. Thus when consumers buy a limited number (relative to the number of consumers in the traditional enterprise market), the implementation of enterprise buy big if product sales in traditional markets, probably because the number is too small to buy products due to price discrimination and achieve its optimal profits, and thus can't produce the maximum price gap.

As can be seen from the above analysis, network buy mode can distinguish consumer groups and consumer markets, so you can use the method of price discrimination to maximize profits manufacturer: buy mode while the network also has advantages compared to traditional trading to cut transaction costs, can manufacturers to achieve decreased costs; another manufacturer for a particular implementation of a network buy mode also bring additional utility. Therefore, the network can buy as manufacturers realize an effective mode of sales revenue and profit

\section{References}

[1] Davenport T H, Prusak L. Working knowledge: How organizations manage what they know[M]. Harvard Business Press, 2000.

[2] Radner R. Competitive Equilibrium under Uncertainty[J]. Alfred Marshall: critical assessments, 1996, 36: 244.

[3] Sedgwick D. "Digital Disruption": are competitive forces in the book publishing marketplace contributing to the utility maximization of consumers' purchasing and price options for ebooks?: An analysis of emerging economic models[J]. 2012.

[4] Ireland J. Lessons for successful BOP marketing from Caracas' slums[J]. Journal of Consumer Marketing, 2008, 25(7): 430-438.

[5]Schwartz M. Third-degree price discrimination and output: generalizing a welfare result[J]. The American Economic Review, 1990: 1259-1262.

[6]. Levi M. Organized fraud and organizing frauds Unpacking research on networks and organization[J]. Criminology and Criminal Justice, 2008, 8(4): 389-419.

[7] Rugullies, E. Power to the Buyer with Group Buying Sites[J]. E-Business Advisor,2001,(10): 10-13.

[8] Achrol R S. Changes in the theory of interorganizational relations in marketing: toward a network paradigm[J]. Journal of the academy of marketing science, 1997, 25(1): 56-71.

[9]Gallini N T, Hollis A. A contractual approach to the gray market[J]. International Review of Law and Economics, 1999, 19(1): 1-21.

[10]Ireland J. Competitive Equilibrium under Uncertainty[J]. Journal of Consumer Marketing, 2010, 33(8): 40-48. 